\title{
RAT STRAIN DIFFERENCES IN THE ACQUISITION OF CONDITIONED AVOIDANCE RESPONSES AND IN THE EFFECTS OF DIAZEPAM
}

\author{
Hisashi KURIBARA, Kyoichi OHASHI and Sakutaro TADOKORO \\ Behavior Research Institute, School of Medicine, \\ Gunma University, Maebashi 371, Japan
}

Accepted August 17, 1976

\begin{abstract}
Adult male albino rats of three strains-Wistar, Sprague-Dawley and Holtzman - were trained to press a lever to avoid electric shocks under Sidman-type (R-S interval $=20 \mathrm{sec} ; \mathrm{S}-\mathrm{S}$ interval $=5 \mathrm{sec}$ ) and discriminated avoidance (ITI $=15 \mathrm{sec}$; warning duration $-5 \mathrm{sec}$ ) schedules, and the acquisition processes of avoidance responses, and the propertics of behavioral baselines were investigated. Under both schedules, Wistar strain rats, though showing poorer results than the other two in the beginning, rapidly progressed with the repetitive training, and finally displayed excellent and stable performances. Sprague-Dawley strain rats were poorer in performances, with delayed acquisition and prolonged warm-up effect in the within-session performance. The results of Holtzman strain rats ranked between the two. After the establishment of stable behavioral baselines under both schedules, $0.5,1.0$ and 2.0 $\mathrm{mg} / \mathrm{kg}$ of diazepam were given subcutaneously, and it was found that in Wistar and Holtzman strain rats, the avoidance responses were inhibited together with increase of delivered shocks in parallel to the doses. In Sprague-Dawley strain rats, however, the avoidance responses were conversely improved with 0.5 and $1.0 \mathrm{mg} / \mathrm{kg}$, while such tended to be inhibited with $2.0 \mathrm{mg} / \mathrm{kg}$, with marked concomitant ataxia. As definite strain differences in avoidance response were demonstrated herein, selcetion of the most appropriate strain should be made when designing behavioral experiments.
\end{abstract}

In experiments with laboratory rats, differences by strains are sometimes observed in physiological and biochemical phenomena (1), or in behavioral phenomena such as emotionality, spontaneous motor activity and acquisition process of conditioned behavior (1-6). On the other hand, it has been reported (7-13) that in assaying psychotropic drugs behaviorally, the effects are greatly affected by the behavioral baselines in the pre-drugged state.

The present work revealed marked difference by strains of rats not only in the acquisition processes of conditioned avoidance responses and in the behavioral baselines established but also in the sensitivities to diazepam. The present work is considered significant, since the avoidance responses are used extensively in the study of psychotropic drugs.

\section{MATERIALS AND METHODS}

Subjects: Experimental animals were adult male albino rats of three strains-Wistar (W), Sprague-Dawley (S) and Holtzman (H)_obtained from the breeding room of Medical School, Gunma Lniversity. W-strain rats have been bred by brother-sister mating for more than 20 years. All were fed a solid diet MF (Oriental Yeast Co., Tokyo) and given tap water ad libitum. 
The avoidance conditionings were started at the ages of 100-120 days when the body weight attained $250-300 \mathrm{~g}$. The breeding conditions remained unaltered after the start of the conditioning, no special care was given, and the animals were allowed to eat and drink freely in their home cages except when they were trained. One training session for a fixed duration was held once a day, and this was repeated at 2-3 day intervals. No rat had more than one training session a day.

Drug: The drug used was diazepam (Cercine Inj., Takeda) which was diluted, immediately before the administration, with a $20 \%$ propylene glycol, and the given volume fixed at $1 \mathrm{ml} / \mathrm{kg}$. Subcutaneous injections were given at intervals of more than one week. One day before and after the administration of the drug, the same volume of solvent alone was given. On the drug testing days, the avoidance responses were observed for $1 \mathrm{hr} \mathrm{im}$ mediately before the administration to check the flucluation of behavioral baseline.

Apparatus and programming: Two conditioned avoidance schedules--Sidman-type and discriminated-were used. The Skinner-boxes and programming systems were the same as used throughout all experiments, and one set was employed in each avoidance training. Schedules and training methods have already been reviewed in detail (14).

Sidman-type avoidance schedule $(15,16)$ : A rat was placed in a Skinner-box, 20(D) $\times 30(\mathrm{~W}) \times 22(\mathrm{H}) \mathrm{cm}$, and shock was delivered by passing $200 \mathrm{~V}, 0.5 \mathrm{~mA}, 50 \mathrm{~Hz}$ AC through the floor grid for $0.5 \mathrm{sec}$ at $5 \mathrm{sec}$ intervals ( $\mathrm{S}-\mathrm{S}$ interval $=5 \mathrm{sec}$ ) by means of a shock scrambler. When the rat pressed a lever (response) set at the side wall of the Skinner-box, the shock presentation was delayed $20 \mathrm{sec}$ from the time of the response ( $\mathrm{R}-\mathrm{S}$ interval $=20 \mathrm{sec}$ ). Thus, if the rat could repeat the lever-pressing at intervals of less than $20 \mathrm{sec}$, shock would always be avoided.

In the present experiment, 4-7 rats of each of the three strains were used. One session lasted for $2 \mathrm{hr}$.

Discriminated avoidance schedule (17-19): A rat was placed in a Skinner-box, 20 (D) $\times 25(\mathrm{~W}) \times 19(\mathrm{H}) \mathrm{cm}$, and shock was delivered every $20 \mathrm{sec}$ by passing current through the floor grid. But at $5 \mathrm{sec}$ prior to the presentation of the shock, visual and auditory stimuli-lighting of a pilot lamp and clicking from a speaker-were given, and such lasted for $5 \mathrm{sec}$ (warning duration $-5 \mathrm{sec}$ ). The first lever-pressing within the duration of the

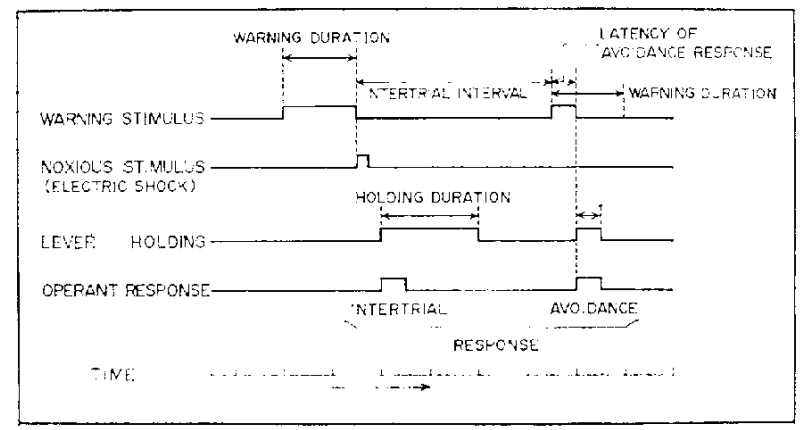

Fis. 1. Schematic diagram of the modificd discriminated avoidance schedule 
warnings stopped these stimuli, and at the same time the shock program returned to the starting point [intertrial interval (ITI) $=15 \mathrm{sec}$. The duration of shock presentation was always $0.5 \mathrm{sec}$. Thus, the present schedule differed from the original ones designed by Solomon and Brush (17) or by Hoffman (18) in that the escape response was not taken into consideration (Fig. 1). The intensity of the electric shock and the method of current passing were the same as in the previous Sidman-type schedule.

In this experiment, 4-6 rats of each of the three strains were used. One session lasted for $2.5 \mathrm{hr}$.

\section{RESULTS}

\section{Difference by strains in the acquisition of Sidman-type avoidance response}

Fig. 2 represents the acquisition processes of rats under Sidman-type avoidance schedule by the response rate (upper) and shock rate (lower). The abscissa denotes the number of sessions and the ordinate the mean numbers per min of responses and shocks in each session. Fig. 3 statistically compares the mean response and shock rates between the three strains.

The response rates were higher in the order of $\mathrm{H}>\mathrm{S}>\mathrm{W}$ up to 3 sessions. The $\mathrm{H}$-strain rats in particular showed a higher response rate from the 1 st session, and the rate remained without any marked change with increase in the number of sessions. In cases of S- and $\mathrm{W}$-strain rats, however, the response rates were gradually elevated with each session, and little difference was observed among the three strains from the 4th to 12 th sessions.

The shock rates were conversely higher in the order of $\mathrm{W}>\mathrm{S}>\mathrm{H}$ until the 2nd session. But the rate for $W$-strain sharply fell in each session, "and the order was $\mathrm{W} \fallingdotseq \mathrm{S}>\mathrm{H}$ in the $3 \mathrm{rd}$, and $\mathrm{S}>\mathrm{W}=\mathrm{H}$ in the 6th session, the last order being maintained in the later sessions. With S-strain rats, the training was continued until the 18 th session without any further improvement. Thus, under Sidman-type

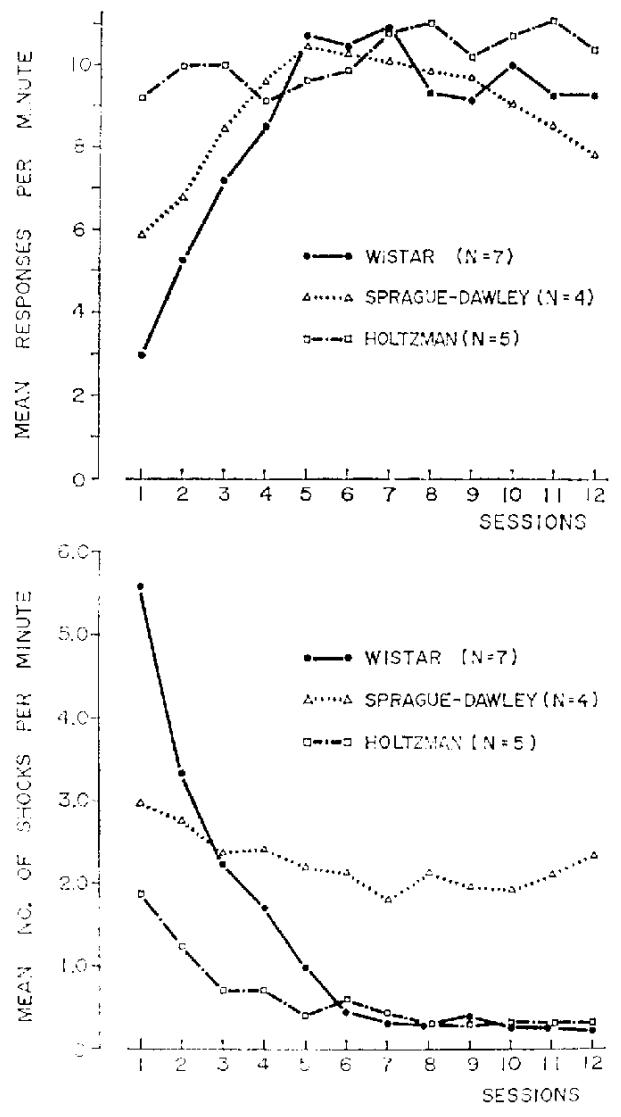

FIG. 2. Difference by rat strains in learning process of Sidman-type avoidance response. R-S interval, $20 \mathrm{sec}$; S-S interval, $5 \mathrm{sec}$; duration of one session, $2 \mathrm{hr}$. Upper, mean number of responses per min; lower, mean number of shocks delivered per min. 


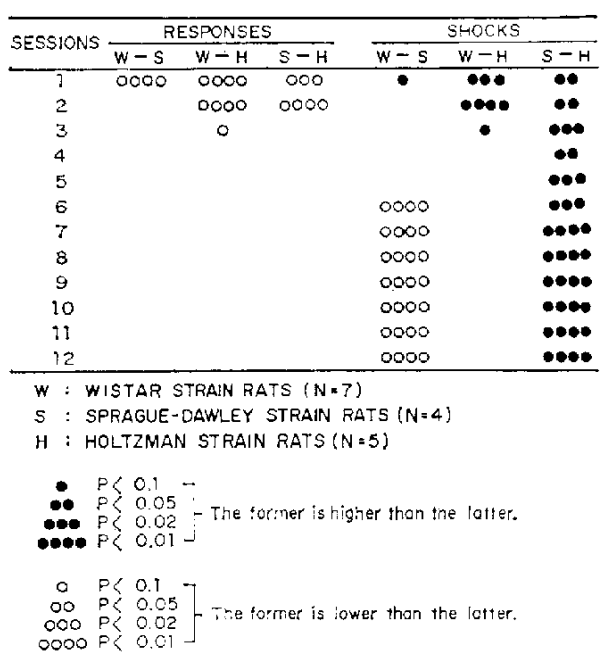

FIG. 3. Pair-wise comparisons of Sidmantype avoidance behavior between strains of rats.

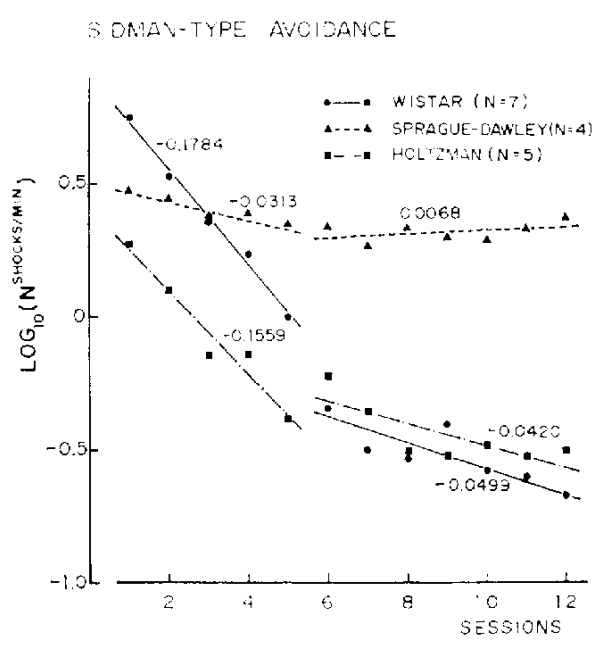

Fig. 4. Difference by rat strains in learning process of Sidman-type avoidance response. The abscissa is the number of sessions, and the ordinate, logarithm of number of shocks per min. The straight lines and figures given were determined by the method of least squares.

avoidance schedule, the behavioral baselines for rats seemed to be established within 6 sessions, and there were marked differences by strains in the acquisition processes and the patterns of the baseline.

Fig. 4 represents the relationship between the logarithms of shock rates and the numbers of sessions, which was previously reported by the authors (19) as a method of quantifying the acquisition speed of rats under Sidman-type avoidance schedule. The straight lines were obtained by the method of least squares in 1-5 and 6-12 sessions, and the figures beside the lines denote their inclinations.

In both the former and later sessions, $\mathrm{W}$ - and $\mathrm{H}$-strains showed nearly the same inclinations, but that for S-strain was markedly different from the other two. It was thus indicated that $\mathrm{W}$ - and $\mathrm{H}$-strain rats possessed nearly the same abilities of acquisition, whereas S-strain had evidently inferior ability.

Differences by strains were also observed in gross behavior of rats during the trainings, thus while many $\mathrm{W}$-strain rats were found crouching in the angle of the box in the early stages of trainings, $\mathrm{S}$ - and $\mathrm{H}$-strain rats tended to run about incessantly.

Regarding within-session performance, warm-up effects were especially observed individually in animals showing the best and worst results. Fig. 5 represents the shock rates of each animal at 30-min intervals in the 1st, 2nd, 3rd, 4th, 6th, 8th, 10th and 12 th session. The upper figures represent the results of the best performers, and the lower, those of the worst performers.

As can be seen herein, both the best and the worst performers of W-strain rats failed to 

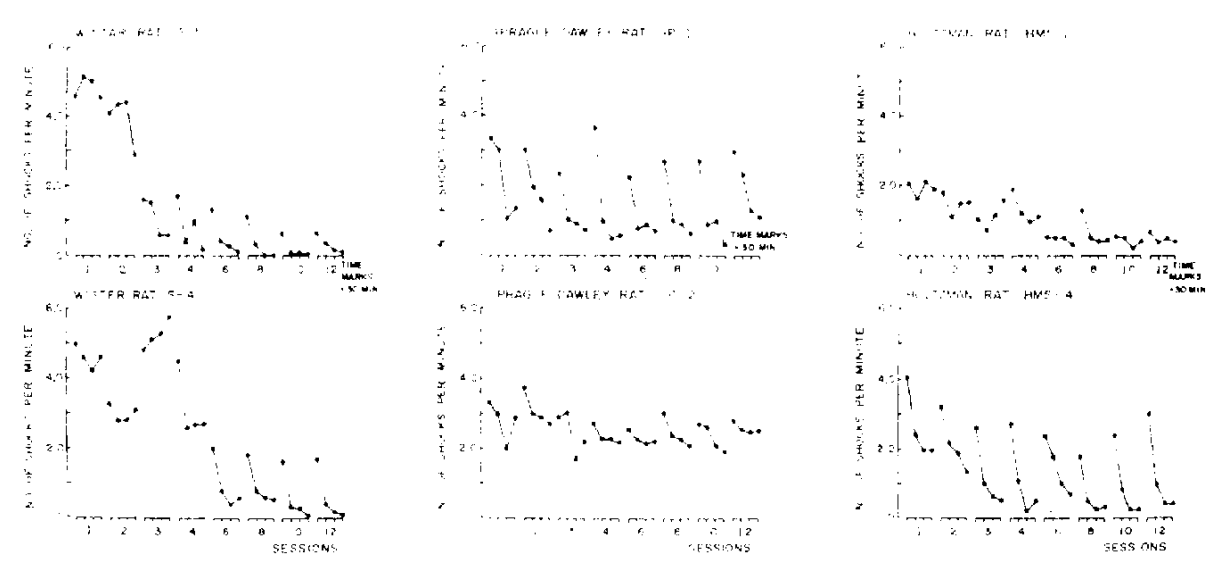

FIG. 5 Difference by strains as seen in changes in shock rates of individual rats in Sidman-type avoidance responses. The rates for the cases of the best performance (upper) and the worst performance (lower) of each strain were determined at 30min intervals of each session. Lcft, Wistar strain rats; middle, Sprague-Dawley strain rats; right, Holtzman strain rats.

perform avoidance in the first session. But in the 6th session and later, not only the best but also the worst performers received the least number of shocks after $30 \mathrm{~min}$, except for some warm-up effect observed immediately after the opening of session. Of S-strain rats, the worst as well as the best displayed some avoidance from the 1st session, and the patterns of within-session changes in shock rate were almost the same in each of 12 sessions and in all cases. Furthermore, even the best performer showed a prominent warm-up effect for $2 \mathrm{hr}$, and only in the latter half of the session did the shock rates tend to decrease. The worst performer failed to show any progress in the learning. Of $\mathrm{H}$-strain rats, both types of performers displayed avoidance in the first session, with the shock rates being lowered. In the 6 th and later sessions, the best performer displayed little warm-up effect, but the shock rate tended to be higher than that seen with W-strain animals. The worst performer exhibited a warm-up effect for $1 \mathrm{hr}$, and such was longer than that of $\mathrm{W}$-strain rats.

Difference by strains in the acquisition on discriminated avoidance response

Fig. 6 represents the acquisition processes of rats under the discriminated avoidance schedule in terms of response rates (upper) and avoidace rates (lower). The abscissa denotes the number of sessions, and the ordinate the response or avoidance rates. Fig. 7 gives the results of statistical comparisons of these rates between the strains.

Under this schedule, longer trainings were needed than under the Sidnan-type for the establishment of behavioral baselines. Difference in the acquisition processes between the strains was essentially the same under the two schedules. Thus the response rates were higher in the order of $\mathrm{S}:-\mathrm{H}>\mathrm{W}$ up to 10 sessions with the exception of the 1st session, and there was no later change among the three strains. The order for avoidance rates was also $\mathrm{S} \fallingdotseq \mathrm{H}>\mathrm{W}$ in the first 8 sessions, but the results of $\mathrm{W}$-strain rats began to improve after several sessions, with avoidance rates attaining stable levels as high as above $95 \%$ on the 

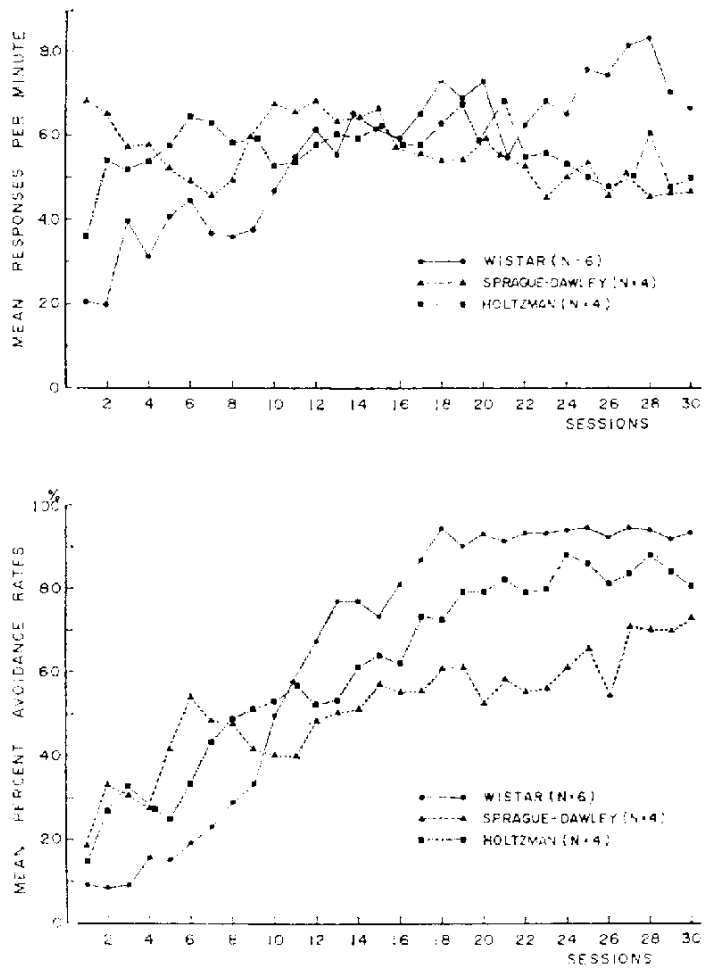

FIG. 6. Difference by rat strains in learning process of discriminated avoidance response. Intertrial interval, $15 \mathrm{scc}$; warning dura tion, $5 \mathrm{sec}$; duration of one session, $2.5 \mathrm{hr}$. Upper, mean number of responses per min; lower, mean of avoidance rates.
FIG. 7. Pair-wise comparisons of diseriminated avoidance behavior between strains of rats.

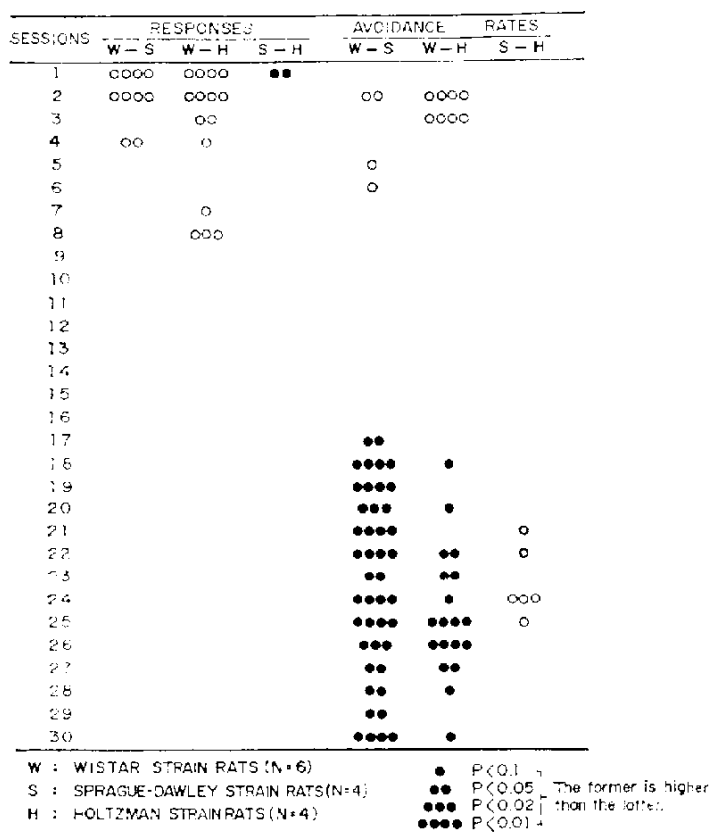


average in the 20 th session and later. Of the $\mathrm{H}$-strain rats, avoidance rates gradually increased until about the 25 th session, when a rate of $80 \%$ was recorded. No further improvement took place and the result remained somewhat below that of the $\mathrm{W}$-strain. S-strain rats gave 60-70\% avoidance rates, with no increase despite repeated training.

As for gross behavior, $\mathrm{S}$ - and $\mathrm{H}$-strain rats tended to be more active in the box much in the same way as was seen under Sidman-type schedule.

Fig. 8 represents avoidance rates and within-session performances of two rats of each strain which gave the best and worst avoidance results, respectively. As in Fig. 4, the results in each of the 1st, 5 th, 10th, 15th, 20th, 25th and the 30th session were shown. The upper figures show the results of the best performers, and the lower, those of the worst performers.

The two rats of $\mathrm{W}$-strain displayed no avoidance in the 1st session, but the best performer, within 10 sessions and the worst performer, within 20, gave avoidance rates as high as $90-100 \%$. Moreover, warm-up effect was never observed in the best case, while in the worst case it lasted no more than 30 min at the longest. The two rats of S-strain displayed some avoidance even in the 1 st session, but marked improvement in avoidance rates such as was seen in the W-strain never occurred. Thus the warm-up effect was manifested for $2 \mathrm{hr}$ even by the best performer, and the maximum avoidance rate never exceeded $80 \%$ in any session. In the worst performer, the warm-up effect remained as long as $2.5 \mathrm{hr}$, and the avoidance rate was only about $60 \%$ even in the last part of session. The two rats of $\mathrm{H}$-strain showed gradually higher avoidance rates with each training, but the improvement was evidently delayed as compared with $\mathrm{W}$-strain rats. Thus it took about 20 sessions of training even for the best performer to attain the within-session avoidance rates of about $90 \%$. Moreover, even at this period of high avoidance rate, warm-up effect lasted for as long as $30 \mathrm{~min}$ to $1 \mathrm{hr}$, and the stability of the baseline within- and between-sessions was evidently inferior to that of $\mathrm{W}$-strain. The worst performer retained the first low avoidance rate for
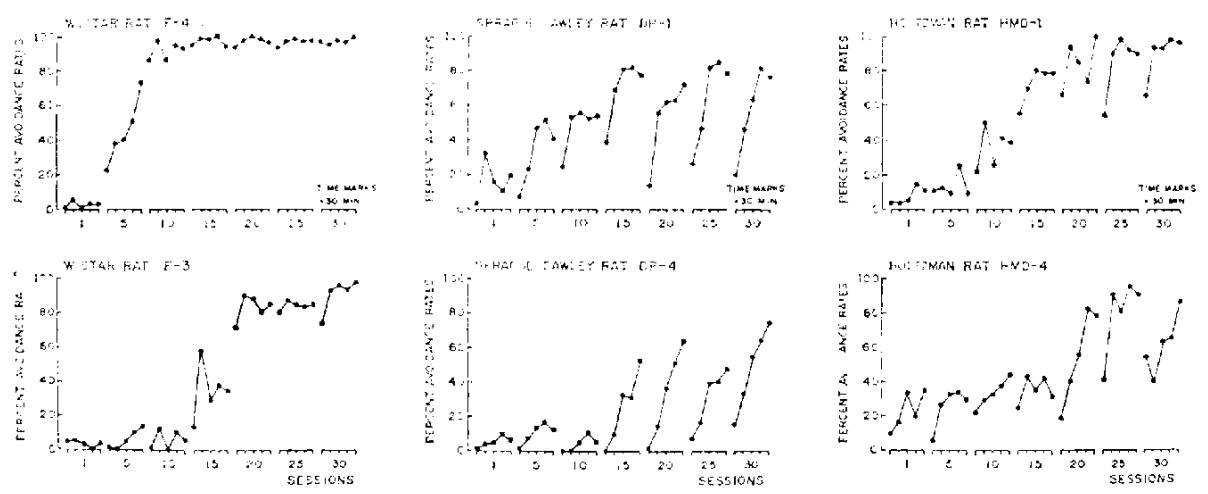

FIG. 8. Difference by rat strains as seen in changes in avoidance rates of individual rats in discriminated avoidance responses. The rates of the cases of the best performance (upper) and the worst performance (lower) of each strain were determined at 30-min intervals of each $2.5 \mathrm{hr}$ session. Left, Wistar strain rats; middle, Sprague-Dawley strain rats; right, Holtzman strain rats. 
about 15 scssions, though performance tended to rise thereafter. However, warm-up effect was observed for as long as $2 \mathrm{hr}$.

Difference in diazepam sensitivity according to strain of rats

Changes in Sidman-type avoidance response's elicited by diazepam administration: After the establishment of behavioral baselines under Sidman-type avoidance schedule by training in more than 12 sessions for $W$ - and $H$-strain rats and in more than 18 sessions for $\mathrm{S}$-strain rats, diazepam was given s.c. in doses of $0.5,1.0$ and $2.0 \mathrm{mg} / \mathrm{kg}$ at one week intervals, and changes in avoidance responses were observed. The results are represented in Fig. 9. On

SIDMAN-TYPE AVOIDANCE
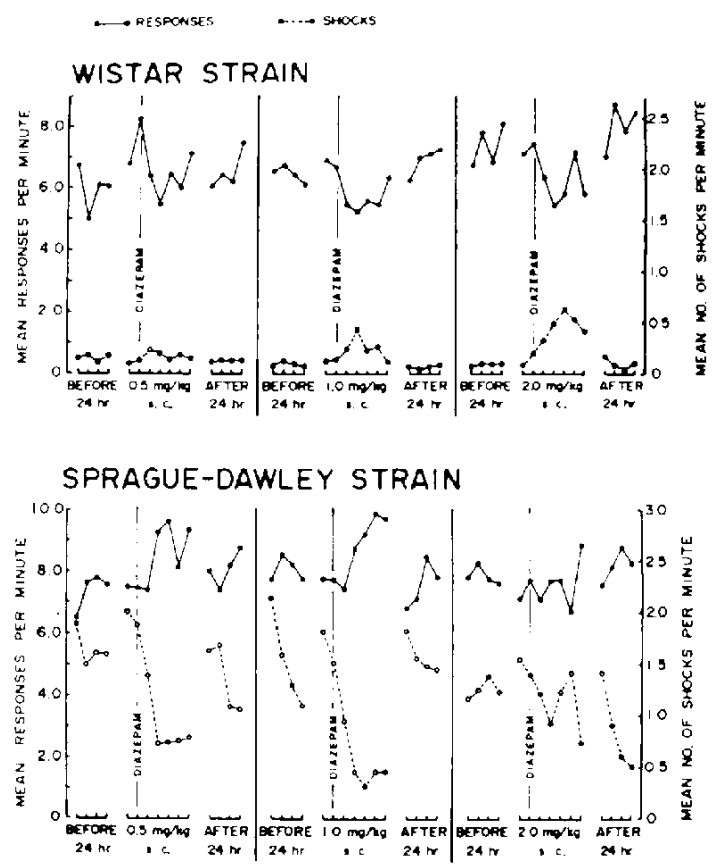

\section{HOLTZMAN STRAIN}

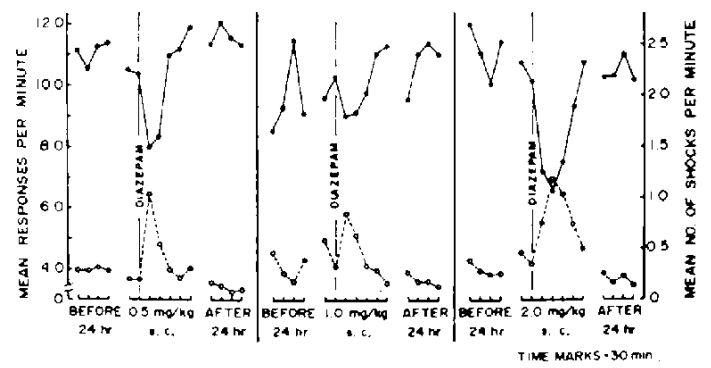

Fig. 9. Effects of diazepam on Sidman-lype ayoidance responses of three strains. Each point represents the mean number of responses and shocks per min at 30-min intervals. Ellect of 20\%, propylene glycol, given before and after the day of diazepam injection is also represented. Upper, Wistar strain rats; middle, Sprague-Dawley strain rats; lower, Holtzman strain rats. 
the previous and the following day of the drug administration, a $20 \%$ propylene glycol, the solvent of diazepam, was given in the same doses as above, and these results were also plotted in Fig. 9. Avoidance responses were observed at least 1 hr before and $2.5 \mathrm{hr}$ after the drug administration in order to trace changes in the drug effect as expressed in response and shock rates.

In cases of $\mathrm{W}$ - and $\mathrm{H}$-strains, diazepam administration inhibited the avoidance responses in parallel to the doses, and as a result, the response rates were lowered while shock rates were elevated. In case of S-strain, however, 0.5 and $1.0 \mathrm{mg} / \mathrm{kg}$ conversely improved the avoidance responses, consequently elevating the response rates, while lowering the shock rates. When $2.0 \mathrm{mg} / \mathrm{kg}$ of diazepam was given, rats displayed marked ataxia, thus making improvement in performance of the S-strain rats inconspicuous.

Changes in the discriminated avoidance responses elicited by diazepam: After the

\section{DISCRIMINATED AVOIDANCE}
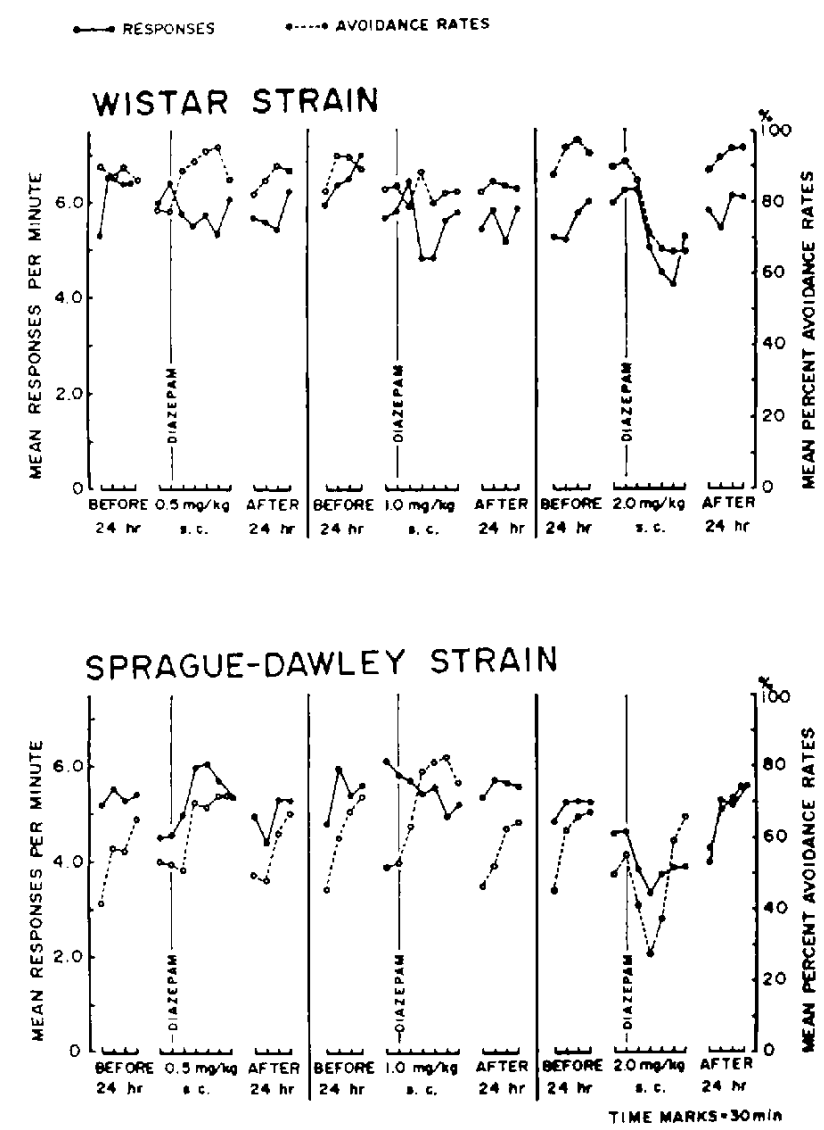

Fig. 10. Effects of diazepam on discriminated avoidance responses of Wistar and Sprague-Dawley strain rats. Each point represents the mean number of responses per min or mean of avoidance rates at 30 -min intervals. The method of representation is the same as in Fig. 9. 
establishment of behavioral baselines under the discriminated avoidance schedule by training in more than 30 sessions for $\mathrm{W}$ - and S-strain rats, $0.5,1.0$ and $2.0 \mathrm{mg} / \mathrm{kg}$ of diazepam were given s.c. to observe changes in the avoidance responses. The results are represented in Fig. 10. The procedure of the drug administration, and the mode of representation of the results are the same as in the cases of the previous Sidman-type schedule. H-strain rats were not dosed.

Also under the discriminated avoidance schedule, similar changes were elicited by diazepam administration. Thus in case of W-strain rats, both response and avoidance rates were lowered in fairly good parallel with the dose of diazepam. In case of S-strain rats, however, 0.5 and $1.0 \mathrm{mg} / \mathrm{kg}$ of the drug improved the avoidance rates, whereas after $2.0 \mathrm{mg} / \mathrm{kg}$, inhibition was seen and a concomitant ataxia developed.

\section{DISCUSSION}

Under the present experimental conditions, W-strain rats were superior to $\mathrm{S}$ - and $\mathrm{H}$ strain rats in the acquisition of the avoidance responses as judged from avoidance and shock rates, and stability of the behavioral baselines. S-strain stood at the last in rank, and $\mathrm{H}$ strain between these two.

Nakamura and Anderson (6) reported that S-strain rats were evidently inferior to Long-Evans strain rats with respect to the establishment process of avoidance response, and Myers (5) pointed out that differences in the strains were dependent on the conditions of training in which S-strain was superior to $\mathrm{W}$-strain when the warning stimulus was pure tone, but vice versa when a buzzer was used. There is also a report (6) that learning ability varies among animals of the same strain if their supplicr, that is, the closed colony is different, since different genetic backgrounds and breeding conditions exert different effects. If so, the present results alone may be inadequatc for the ranking of learning ability among strains. It is, however, noteworthy that the three strains displayed an identical order of performance ability under the two different schedules, thus manifesting their respective characteristics in avoidance conditioning. Previously the authors $(19,20)$ reported that the temporal parameters such as R-S and S-S intervals in Sidman-type avoidance schedule, and ITI in the discriminated avoidance schedule had little influence on the learning speed. Hoffman et al (21) pointed out that the change in shock intensity produced little effect on the avoidance performance. It is therefore considered reasonable to estimate the general trend of avoidance conditioning of each strain under the experimental conditions, where the same apparatus, the same shock intensity and the same temporal parameters are used throughout the experiment.

Also with regard to gross behavior during the training, $\mathrm{S}$ - and $\mathrm{H}$-strain rats were more active in the Skinner-boxes from the beginning, while W-strain rats tended to be motionless, thus exhibiting the different characteristics seen with different strains. We assumed that the accidental lever pressing may be higher in the former two than in the latter.

A prominent warm-up effect was occasionally observed in the within-session performances of both the best and worst performers of S- and $\mathrm{H}$-strains, again strongly indicating 
a difference in strains. Nakamura and Anderson (6), Hoffman et al $(18,21)$ and Kamin $(22,23)$ consider that the warm-up effect may reffect emotionality, resulting from exposure to shock during the session, or heightened motivation for avoidance, or the between-session maintenance of these factors. From this viewpoint, the emotionality or motivational reactivity may be higher in the order of $\mathrm{W}>\mathrm{H}>\mathrm{S}$. These observations alone do not however, explain the difference by rat strains as revealed in the present experiment. Results from experiments on unconditioned performances should be utilized for purpose of comparison.

S-strain rats, which gave the poorest performance in the avoidance tests, displayed different responses to diazepam from that of the other two strains. Takaori et al (9) and Bignami et al (10) stated that diazepam administration to rats of the same strain improved the avoidance response when such was previously inferior, but inhibited the response when such was previously superior. Essentially similar effects of diazepam were seen in the present work. This can be explained to some extent by the rate dependency $(11,12)$, that is, diazepam may exert an inhibitory effect on animals with a high rate of efficient responses, say of $\mathrm{W}$-strain, and an accelerative effect on those with low response rates, say of S-strain, since there is no difference in the response rate between these two strains.

The results of the present experiment indicate the necessity of careful selection of the strain in designing behavioral experiments and in analyzing the results.

\section{REFERENCES}

1) Coyle, J.T. JR., Wender, P. And Lipsky, A.: Psychopharmacol, 31, 25 (1973)

2) Broudhurst, P.L. : J. comp. physiol. Psychol. 51, 55 (1958)

3) Wilcock, J. And Broudhurst, P.L.: J. comp. physiol. Psychol. 63, 335 (1967)

4) SChaffer, V.H.: J. comp. physiol. Psychol. 52, 120 (1959)

5) MYERS, A.K.: J. comp. physiol. Psychol. 52, 381 (1959)

6) Nakamura, C.Y. and ANderson, N.H.: J. comp. physiol. Psychol. 55, 740 (1962)

7) Fleming, J.C. ANd Brovdiursi, P.L.: Psychopharmacol. 42, 147 (1975)

8) CARG, M.: Psychopharmacol. 14, 432 (1969)

9) TAKaORI, S., YADA, N. AND Mori, G.: Japan. J. Pharmacol. 19, 587 (1969)

10) Bignami, G., de Acetis, L. And Gatti, C.L.: J. Pharmacol. exp. Ther. 176, 725 (1971)

11) Kelleher, R.T. and Morse, W.H. : Ergebn. Physiol. 60, 1 (1968)

12) Dews, P.B.: Fedn Proc. 17, 1024 (1958)

13) Heisf, G.A. ANd Bori, E.: Psychopharmacol. 3, 264 (1962)

14) Tadokoro, S. And OGawa, H.: Basic Pharmacol. Ther. 2, 1189 (1974) (in Japanese)

15) SIDMAN, M.: Science 118, 157 (1953)

16) Sidman, M.: Operant Beharior, Edited by HoniG, W.K., p. 448, Appleton-Century-Crofts, New York (1966)

17) Solomon, R.L. AND Brush, E.S.: Nebraska Symposium on Motivation, Edited by Jones, M.R., p. 212, Univ. Nebraska Press, Lincoln (1956)

18) Hoffman, H.S.: Operant Behavior, Edited by Hosig, W.K., p. 499, Appleton-Century-Crofts, New York (1966)

19) Kuribara, H., Okuitumi, K. and Tadokoro, S.: Japan. J. Pharmacol. 25, 541 (1975)

20) Tadokoro, S., Okulzumi, K., Kuribara, H. and OGawa, H.: Folia pharmacol. japon. 70, 67P (1974) (in Japanese)

21) Hoffman, H.F., Fieshler, M. And Chovny, H.: J. exp. Anal. Behav. 4, 309 (1961)

22) Kamin, L.J.: J. comp. physiol. Psychol. 50, 457 (1957)

23) Ka.MI, L.J.: J. comp. physiol. Psychol. 56, 713 (1963) 